\title{
Resilience to Early Family Risk Moderates Daily Stress and Affect on Cortisol Diurnal Slope associations: A 14-Day Ecological Momentary Assessment Study
}

\author{
Natasha Yan Chi Tung \\ Monash University \\ Yang Yap \\ Monash University \\ Bei Bei \\ Monash University \\ Linda Luecken \\ Arizona State University \\ Joshua Wiley ( $\square$ joshua.wiley@monash.edu ) \\ Monash University
}

\section{Research Article}

Keywords: cortisol, diurnal rhythm, stress, affect, resilience, EMA

Posted Date: September 20th, 2021

DOI: https://doi.org/10.21203/rs.3.rs-874083/v1

License: (c) (1) This work is licensed under a Creative Commons Attribution 4.0 International License.

Read Full License 


\section{Abstract}

\section{Objective}

This study examined whether resilience capacity moderates the impact of daily perceived stress and affect on cortisol diurnal slope among relocated emerging adults.

\section{Methods}

Relocated undergraduates ( $N=98$; aged 18-25 years) were recruited from three groups: Resilient, Vulnerable, and Control. Mixed-effects models were used to test the unique effects of perceived stress, negative affect, and positive affect $x$ group interactions on diurnal cortisol slope across 14 consecutive days.

\section{Results}

The Resilient group did not moderate the associations between daily stress or affect on cortisol diurnal slope. Instead, both the Resilient and Vulnerable groups with early family risk, showed a steeper diurnal slope unique to higher stress and a flatter slope unique to higher NA.

\section{Conclusions}

Results suggest that an adverse early family life was significantly associated with altered cortisol diurnal slope outcomes to stress (i.e., demand) and negative affect (i.e., distress). These associations were not attenuated by current resilience capacity.

\section{Introduction}

Cortisol is a stress-sensitive steroid hormone regulated by the hypothalamic-pituitary-adrenal (HPA) axis that prepares the body to mobilize energy in managing threat (Ross et al., 2014). In humans, the cortisol diurnal rhythm is the daily circadian pattern of cortisol secretion peaking around 20 - 30 minutes after awakening followed by a decline throughout the day to its nadir 2 to 3 hours after sleep onset (Ross et al., 2014). Cortisol's diurnal slope is derived from this decline from wake cortisol levels to pre-sleep cortisol levels, with a steady decline indicating healthy cortisol regulation (Segerstrom et al., 2014). Flattened cortisol diurnal slopes occur when there is lower wake cortisol levels or sustained elevation of cortisol levels at pre-sleep (Miller et al., 2017). Flattened cortisol diurnal slopes are linked to poorer emotional and physical health such as cardiovascular diseases in a meta-analysis of 80 studies across all ages ranging from children to older adults (Adam et al., 2017).

Chronic stress such as a risky early family background can influence the development and adult functioning of the HPA-axis (trait-like variation). Cortisol diurnal slope also responds to acute changes in individuals' everyday experiences (state-like variation), notably in response to stress and affect (Ross et al., 2014). Although daily stress and affect co-occur, they are conceptually distinct. Together, stress, 
negative affect (NA), and positive affect (PA) capture a range of daily experiences including situational demand (stress), negative experiences (NA), and positive experiences (PA) (Selye, 1976). Stress and affect can have unique effects on cortisol, yet these are rarely separated in the literature (van Eck et al., 1996; Watson \& Pennebaker, 1989).

Individuals differ in their experience of and physiological response to situations depending on their psychological appraisal (DiCorcia et al., 2013; Wang \& Hoyt, 2018). Individuals with high resilience capacity, defined as the trait of bouncing back from hardship (Smith et al., 2008), evaluate challenges as manageable and respond better to stress. However, few studies have examined the role of resilience capacity, stress, and affect with cortisol diurnal slope on a daily basis, with most studies focussing on momentary cortisol levels or reactivity. To our knowledge, no studies have examined whether resilience capacity moderates the links of naturally occurring daily stress and affect with cortisol diurnal slope.

\section{Early Family Risk on Cortisol Diurnal Slope}

Research on the impact of early family risk as a type of chronic stress on cortisol diurnal slope has commonly found a flattened diurnal slope with elevated cortisol throughout the day among exposed children, attributed to a desensitization of the HPA-axis from over-engagement to recurring stressors (Gunnar \& Vazquez, 2001). These studies typically focussed on participants from backgrounds with highly adverse or abusive features, including children raised under institutional neglect (Carlson \& Earls, 1997), with childhood trauma (O'Connor et al., 2020), or with Child Protective Services involvement (Bernard et al., 2015). Recent studies included parenting features such as poor parental monitoring (Martin et al., 2014) and maternal neglect (Buhler-Wassmann et al., 2020).

\section{Impact of Daily Acute Stress and Affect on Cortisol Diurnal Slope}

Acute stress differs from chronic stress in the impact on cortisol diurnal slope but is rarely uniquely studied (Klein et al., 2016). Yet, the daily variations in cortisol to momentary changes are important to study as they exert downstream biological processes relevant to disease (Ross et al., 2014). A naturalistic daily study showed cortisol diurnal slopes are steepened due to higher wake cortisol levels among older adults who reported higher frequency of stressors (Stawski et al., 2013). Overall, there is a lack of daily studies examining the relationship between acute stress and cortisol diurnal slope, with most examining momentary cortisol levels and finding increases during the anticipation and experience of stressors (Smyth et al., 1998; van Eck et al., 1996), and to higher perceived stress (Sladek et al., 2016). Higher momentary and wake cortisol levels with higher stress may be explained by the higher engagement of HPA-axis to meet the demands of the situation (Wong et al., 2012). This adaptive response of diurnal cortisol activation if sustained can result in long-term physical and mental health issues (Miller et al., 2007).

Beyond stress, NA and PA influence cortisol outcomes. Emotional responses to stressors, rather than chronic or daily stressors, predicted higher cortisol secretion levels in some (Jacobs et al., 2007; Smyth et al., 1998; van Eck et al., 1996) but not all (Stawski et al., 2013) studies. One study found significant 
associations between NA and cortisol diurnal slope independent of stress (Doane \& Adam, 2010). However, affect may be influenced by antecedent stressors (Stawski et al., 2013). Hence, separate assessment of affect and stress and simultaneous examination in one model is necessary to distinguish their unique influences on cortisol diurnal slope.

Higher NA levels are associated with flatter cortisol diurnal slope among adolescents (DeSantis et al., 2007; Hoyt et al., 2015) and among adults (Adam et al., 2006). The experience of sadness manifested in social withdrawal and behavioural inactivity may result in lower wake cortisol levels or the experience of anger and tension may result in higher pre-sleep cortisol levels. The few daily studies that examined PA and cortisol diurnal slope found steeper diurnal slopes with higher PA among midlife healthy adults (Miller et al., 2016) and high school students (Hoyt et al., 2015), but no impact of PA on wake cortisol levels. The steeper decline in cortisol slope in these studies not driven by a higher wake cortisol level was interpreted as indicative of healthy functioning.

\section{Resilience Capacity on Cortisol Diumal Slope}

To our knowledge, no studies have investigated if psychological resilience moderates daily stress/affect associations with cortisol diurnal slope. However, there are findings suggestive of the protective role of resilience or resilience-related constructs on cortisol metrics. Adults with higher psychological resilience had a weaker association between perceived stress and hair cortisol levels over 3 months compared to those with low resilience (Lehrer et al., 2020). High-risk individuals with high emotional regulation show minimal dysregulation in average basal cortisol across time (Kliewer et al., 2009). Among children of parents with HIV, resilience was associated with steeper cortisol diurnal slopes via less experienced stigma (Chi et al., 2015).

\section{Aims and Hypotheses}

The relations between resilience capacity, momentary stress, and affect with daily diurnal cortisol slopes remains underexplored. Further, resilience capacity should be most helpful in the presence of risk, which often is not captured in resilience studies (Colich et al., 2020). Using retrospective reports of family risk as an index of prior adversity, our study recruited participants from three groups: (1) Resilient, including individuals who originated from risky families and reported high current resilience capacity, (2) Vulnerable, including individuals from risky families but with low reported current resilience capacity, and (3) Control, including individuals with low early family risk and average current symptoms of anxiety and depression. Participants were repeatedly assessed in their daily stress, affect, and cortisol at specific timepoints using ecological momentary assessments (EMA). All participants were emerging adults who relocated for tertiary studies so that their daily experiences represent a known stressful transition period (Arnett, 2000).

We hypothesized that 1a) across the sample, a steeper, negative cortisol diurnal slope would be associated with higher perceived stress, higher PA, and lower NA, 1b) on average, the Resilient group would demonstrate a similar diurnal cortisol slope as the Control group whereas the Vulnerable group 
would demonstrate a flatter diurnal slope than the Resilient or the Control groups. Our study further explored whether the relation between stress and affect on diurnal cortisol slope is moderated in the Resilient group compared to the similarly high-risk Vulnerable group. Specifically, compared to the Vulnerable group, the Resilient group individuals were expected to have a weaker association between 2a) stress and diurnal cortisol slope, b) NA and diurnal cortisol slope, and c) PA and diurnal cortisol slope.

\section{Method}

\section{Transparency and Openness}

We report how we determined our sample size, all data exclusions, and all measures included. Analysis code [https://doi.org/10.26180/14703843] and research materials [https://doi.org/10.26180/14593986.v1] [https://doi.org/10.26180/14594238.v2] are available. Data will be made available on reasonable request and are planned for future public sharing in redacted form. The study and analysis plan were not pre-registered.

\section{Participants}

A total of 98 international or interstate students aged 18 to 25 years old $\left(M_{\text {age }}=20.54, S D_{\text {age }}=1.64\right)$ who moved interstate or overseas to commence tertiary studies in Melbourne, Australia completed the study between March 2019-June 2020. Data from 95 participants with viable cortisol samples were used. Supplementary Figure 2 shows the participant flow chart and eligibility. Reporting follows the Strengthening the Reporting of Observational Studies in Epidemiology (STROBE) and Checklist for Reporting EMA Studies (CREMAS) reporting guidelines (Liao et al., 2016; Von Elm et al., 2008; Supplementary Table 2 and 3). A-priori power analysis conducted through $\mathrm{G}^{*}$ Power (Faul et al., 2007) indicated that with $\mathrm{a}=0.05,10$ total predictors, and testing two predictors at once (appropriate as we have three groups), 75 participants, assuming a 75\% compliance rate of 2 daily cortisol assessments across 14 days and intraclass correlation coefficients (ICCs) of 0.20 or 0.40 for cortisol provides $175-315$ effective independent observations which provides $80 \%$ power to detect a medium effect size (Cohen's $f^{2}$ $=.15$ ) or a small-to-medium effect size (Cohen's $f^{2}=.05$, roughly equivalent to a Pearson's $r=0.20$ ). More participants were recruited to allow for attrition and other aims and outcomes from the broader study.

\section{Grouping}

Participants were grouped based on their responses to the Risky Family Questionnaire (RFQ; Felitti et al., 1998; Taylor et al., 2004), Brief Resilience Scale (BRS; Smith et al., 2008), and PROMIS Anxiety and Depression scores (Cella et al., 2010) completed at baseline (more details on these measures in Supplementary section). To maximize individual variability in this study, only participants who scored within the top and bottom tertile of family risk were invited to this daily study. A tertile split has similarly been used in other resilience studies among students (Pidgeon et al., 2014). The Resilient group was defined as RFQ $\geq 29$ and $B R S \geq 3.6$, corresponding roughly to the top tertile in our baseline sample of 380 participants. The Vulnerable group was defined as RFQ $\geq 29$ and BRS $\leq 3$, corresponding to roughly 
the top tertile RFQ in our baseline sample and below mean BRS. Research has shown that below average resilience is associated with below average well-being and can indicate risk (Tomyn \& Weinberg, 2018) so our resilience cut off was chosen as approximately the mean BRS from our baseline data. The comparison Control group was defined as RFQ $\leq 21$, approximately the bottom tertile in our population, and T-scores $<60$ on PROMIS anxiety and depression symptoms, at most mild symptoms (Cella et al., 2010) (Supplementary Figure 1 and Figure 2).

\section{Design and procedure}

Monash University Human Research Ethics Committee (\#17281) approved the study. Informed consent was obtained from all participants and the study was performed in accordance with relevant guidelines and regulations. Participants who completed the baseline questionnaire ( 45 minutes) and met eligibility were invited to the daily study (Figure 1; Supplementary Figure 2 ). This daily study employed an intensive longitudinal observational design with daily repeated EMA across 14 days assessing participants' stress and affect at 4 time points daily (Figure 1) using a mobile application (MetricWire) on iOS or Android. Participants collected saliva samples using a synthetic cotton roll in Salivette tubes (SARSTEDT, Australia) immediately after waking and just before bedtime for 14-consecutive days. Participants recorded the date and time of saliva collection on the tube label, then attached a photo of the label to their morning and pre-sleep surveys. Recorded collection time was validated against the digital photo timestamp and self-reported wake/sleep times to monitor compliance. Participants were given a set of saliva collection compliance behaviour instructions (Supplementary section). They were encouraged to accurately report violations of these instructions, if any, in their pre-sleep surveys. Samples were removed if they did not meet collection criteria. Samples were stored in subjects' home freezers until transport to the lab, where uncentrifuged samples were kept at either -25 or $-80^{\circ} \mathrm{C}$ freezers until analysis. The samples were then sent to the University of Dresden for assay analyses.

\section{Measures}

Salivary Cortisol Diurnal Slope. Our study derived diurnal slopes from 2 cortisol samples on each of the 14 days, based on Segerstrom and colleagues' (2014) finding that diurnal slopes measured with this 2sample approach (one at wake time and the other $9 \mathrm{pm}$ ) correlated .97 and .99 with diurnal slopes measured using 4 and 3 samples, and was better able to detect between- and within-person differences compared to more samples across fewer days. Raw cortisol values were natural log transformed to reduce skewness.

Stress. Perceived stress was measured using a single item "Since the previous survey, how stressful has your day been?" rated from 0 (Not at all stressful) to 10 (Very stressful).

Affect. Affect was measured using 14 items from the Positive and Negative Affect Schedule-Expanded version (PANAS-X) scale (Watson \& Clark, 1998). Participants were asked to rate how much they experience that affect since the previous survey or since wake for the first survey of the day based on "today", on a 5-point Likert scale with $0=$ "not at all" to $4=$ "extremely". Negative affect ( 7 items; e.g., 
"irritable", "disgusted with self", "sad", "guilty", "nervous", "lonely", "afraid") had good between and adequate within reliability $\left(\omega_{\text {between }}=0.89 ; \omega_{\text {within }}=0.62\right)$. Positive affect (7 items; e.g., "confident", "relaxed", "happy", "enthusiastic", "calm”, "cheerful”, "at ease") had good between and within reliability $\left(\omega_{\text {between }}=0.96 ; \omega_{\text {within }}=0.81\right)$.

Covariates. Covariates were selected a priori based on literature. Baseline covariates included age (years) and sex (male/female) (Kudielka et al., 2009), subjective socioeconomic status (McLachlan et al., 2016), race (coded as Asian/White/Others) (Deer et al., 2018), nationality (international/interstate) (Khawaja \& Dempsey, 2008), English language acculturation (using the adapted Short Acculturation Scale for Hispanics to refer to participants' native language instead of Spanish, with a score range of 1 [low] 5[high]), time spent in Melbourne, COVID-19 period (pre [before Victoria lockdown 08/03/2020] vs during), body mass index (BMl; $\mathrm{kg} / \mathrm{m}^{2}$ from self-reported height and weight) and alcohol consumption (coded abstainers/moderate/at-risk) (Kudielka et al., 2009). Responses for sex and gender were equivalent in our data, hence combined into one variable. Daily covariates included number of daily stressors, study day, month to account for seasonal variations in weather and progression in University semester, day of the week to account for differences in stress and affect during weekends vs weekdays (Marchand et al., 2014), compliance behavior violations (coded yes/no), and medication (coded taking vs not taking) during study period. There are no differences in results with including or excluding trait anxiety and depression (Van den Bergh et al., 2008) as covariates.

\section{Analysis}

Data were analyzed using R version 3.6.3 (R Core Team, 2019). Mixed models were estimated using Ime4 v1.1-23 with restricted maximum likelihood. ImerTest v3.1-2 was used for degree of freedom and significance testing. All mixed models included a random intercept by participant to address nonindependence and all covariates. Significance was set at $a=.05$, two-tailed. Visual model diagnostics were checked to evaluate assumptions. All assumptions were met. Simple slopes were calculated for any significant interactions using high and low levels of perceived stress $(4.24,0.45), N A(2.06,1.04)$ and PA $(1.57,3.64)$, determined based on the $90 \%$ and $10 \%$ percentiles in our sample.

\section{Hypothesis 1: Main Effects of Perceived Stress, NA, PA, and Group on Cortisol Diurnal Slope (Two-way}

Interactions). This model tested whether between-person differences in daily perceived stress, NA, PA, and group were associated with cortisol diurnal slope via two-way interactions between daily stress/affect variables and time [wake or pre-sleep].

Hypothesis 2: Moderation of Group on Daily Stress/Affect-Cortisol Diurnal Slope associations (Three-way Interactions). This model tested the between-group differences in interactions with daily stress, NA and PA on cortisol diurnal slope (i.e., three-way interactions between groups [Resilient; Vulnerable; Control], daily stress/affect, and time [wake or pre-sleep] on cortisol levels).

\section{Results}




\section{Description of the Sample}

Table 1 shows the descriptive statistics and Supplemental Table 1 shows bivariate correlations. Most participants were female, of Asian descent, and were international students who spent less than a year in Melbourne. Participants exhibited the expected diurnal cortisol profile with average wake and pre-sleep cortisol of 11.32 and $1.29 \mathrm{nmol} / \mathrm{l}$, which are comparable to healthy subjects in population-based studies (Shin et al., 2011). None of the demographic variables or covariates were significantly associated with average cortisol levels except for age $(r=-0.28, p=.005)$ and time spent in Melbourne $(r=-0.22, p=.029)$. Participants reported average levels of daily stress, NA, and PA that were comparable to other young adult samples (Merz \& Roesch, 2011; Ong et al., 2016). The Resilient and Control groups did not meaningfully differ (Chen et al., 2018) on anxiety and depression symptoms, both showing lower symptoms than the Vulnerable group (Table 1).

\section{Compliance}

The 95 participants provided 4,333 surveys ( $74 \%$ completion rate) and 2,345 viable saliva samples ( $85 \%$ compliance rate) across 14 days, with no significant differences across groups ( $p=.92$ and $p=.39$ respectively). In total, there were 71 (5.5\%) saliva samples with reported violations of compliance behaviour, controlled for in analyses.

\section{Hypothesis 1A: Steeper, negative cortisol diurnal slope will be associated with higher perceived stress,} higher PA, and lower NA

There was a significant interaction effect for PA with cortisol diurnal slope $(b[95 \% \mathrm{Cl}]=-0.09[-0.17,-0.00]$, $p=.046)$ where higher levels of PA predicted a steeper, negative diurnal cortisol slope. No significant interaction was found for perceived stress $(p=.23)$ or NA $(p=.065)$ with cortisol diurnal slope (Table 2$)$.

Hypothesis 1B: On average, the Resilient group will demonstrate a similar negative diurnal cortisol slope as the Control group whereas the Vulnerable group will demonstrate a flatter diurnal slope than the Resilient or the Control groups.

There were no significant differences in cortisol diurnal slope between all three groups (all $p \geq 0.14$, Table 2).

Hypothesis 2A: Compared to the Vulnerable group, the Resilient group will have a weaker association between stress and cortisol diurnal slope.

Contrary to prediction, the Resilient and Vulnerable groups did not differ in their interactions with stress on cortisol diurnal slope, indicated by the absence of significant three-way interaction $(p=.10)$ (Table 3 ). Compared to the Control group, both the Resilient $(p<.001)$ and Vulnerable $(p=.002)$ groups showed a stronger association between high stress and steeper diurnal slope (Table 3, Figure 2A). Overall, groups significantly interacted with stress and cortisol diurnal slope at a small effect size $f^{2}=0.009, p<.001$. 
The steeper decline for the Resilient group at high stress was accompanied by a non-significant higher wake cortisol level at high stress compared to low stress $(1.87, p=.12)$, which was also significantly higher than the Control group $(p=.03)$. The steeper decline for the Vulnerable group was accompanied by a non-significant lower pre-sleep cortisol level at high stress $(-0.44, p=.11)$. In contrast, the Control group showed a significant flatter diurnal slope with high stress $(p=.006)$ accompanied by lower wake cortisol levels $(-0.87, p=.09)$.

\section{Hypothesis 2B: Compared to the Vulnerable group, the Resilient group will have a weaker association between NA and cortisol diurnal slope.}

Contrary to prediction, the Resilient group showed a significantly larger interaction effect with NA levels on cortisol diurnal slope compared to the Vulnerable $(p=.029)$ and Control $(p=.002)$ groups, indicated by significant three-way interactions (Table 3). Compared to both the Vulnerable and Control group, the Resilient group showed a significantly flatter diurnal slope at high NA (Table 3; Figure 2B). The Vulnerable group also showed a significantly larger interaction effect $(p=.020)$ and a flatter diurnal slope at high NA $(p=.033)$ compared to the Control group. Groups significantly interacted with NA and cortisol diurnal slope at a small effect size $\left(f^{2}=0.006, p=.003\right)$.

The flatter slope of the Resilient group was accompanied by both non-significant lower wake cortisol $(-1.38, p=.09)$ and higher pre-sleep cortisol levels at high NA $(0.20, p=.78)$ while the flattened slope of the Vulnerable group was accompanied by significant higher pre-sleep cortisol levels $(0.39, p=.04)$. In contrast, the Control group showed no significant changes in cortisol diurnal slope by NA $(p=.11)$.

\section{Hypothesis 2C: Compared to the Vulnerable group, the Resilient group will have a weaker association between PA and cortisol diurnal slope.}

Contrary to prediction, the Resilient and Vulnerable groups did not differ in their interactions with PA levels on cortisol diurnal slope, shown by the absence of three-way interaction ( $p=.87)$ (Table 3). Both the Resilient and Vulnerable groups showed no significant changes in cortisol diurnal slope to PA (Table 3; Figure 2C). The Control group showed a significant steeper negative diurnal slope at high PA $(p=.003)$, although not significantly different than either the Vulnerable $(p=.061)$ nor Resilient $(p=.30)$ groups.

\section{Discussion}

We found no overall changes in cortisol diurnal slope to higher stress and NA nor overall group differences in basal cortisol diurnal slope. When cortisol diurnal slope changes to stress and affect were examined by group, significant differences emerged. The Resilient group did not show the expected moderation effect on cortisol diurnal slope compared to their Vulnerable counterparts. Instead, the Resilient and Vulnerable groups both demonstrated a steeper diurnal cortisol slope with high stress compared to the Control group. Additionally, the Resilient group showed a flatter diurnal slope with high NA compared to the Control or Vulnerable groups. 
Hypothesis 1 was partially supported. Higher PA was associated with a steeper, negative cortisol diurnal slope, consistent with previous research (Miller et al., 2016; Hoyt et al., 2015). There were no significant associations between daily stress and NA with cortisol diurnal slope. The absence of a significant association for daily stress is consistent with similar null findings in other studies that controlled for affect as our study did (Jacobs et al., 2007; Smyth et al., 1998; van Eck et al., 1996). Other studies also found null associations between NA with cortisol diurnal slopes or associations in the opposite direction to our hypothesis, requiring the consideration of arousal levels of NA or the interpretation of NA as harmful or not in measuring these associations (Miller et al., 2016; Park et al., 2020). Differences in our findings compared to existing literature also may be attributable to our collection of 2 saliva samples daily for 14 days, which better characterizes between-subject differences on cortisol slope (Segerstrom et al., 2014). Contrary to our prediction, the Vulnerable group did not exhibit an overall flatter cortisol diurnal slope than the Resilient or Control groups, perhaps because their early family risk was not at the severity or chronicity of abuse or maltreatment where flatter cortisol diurnal slopes previously have been shown.

Hypothesis 2 was not supported. The Resilient group did not show the hypothesized weakened interaction with stress/affect on cortisol diurnal slope. Instead, for high stress, both the Resilient and Vulnerable groups had steeper diurnal slopes compared to the Control group. The Resilient group's steeper slope accompanied by higher wake cortisol levels may be explained by a greater engagement of the HPA-axis in approaching and managing demands (Sladek et al., 2016). The wake cortisol levels in the Vulnerable group did not change by stress, which may be explained by controlling NA (i.e., emotional distress) that often accompanies managing stress. Curiously, the Control group showed a flatter diurnal slope to high stress, contrary to existing literature (Stawski et al., 2013). The reason is unclear but our study examining the unique effects of stress, NA, and PA means perceived stress captures the experience of challenge/demand with neutral valence, perhaps explaining this distinct finding (Balters et al., 2020).

At high NA levels, the Resilient group showed a significantly flatter cortisol diurnal slope compared to both the Vulnerable and Control groups. Our assumption was that the better psychological outcomes found among individuals with high resilience capacity compared to those with low resilience capacity (Werner, 1993) would translate to healthier physiological outcomes in adverse situations. The flatter cortisol diurnal slope among the Resilient group compared to the similarly high-risk Vulnerable group may be interpreted as a heightened physiological sensitivity to emotional distress, reflecting a physiological cost for psychological adjustment (Brody et al., 2013). These speculations need further exploration. Nevertheless, both the Resilient and Vulnerable groups showed flatter diurnal slope to high NA, which is indicative of the allostatic load of higher family risks resulting in heightened vigilance to threat (i.e., negative experiences) and therefore greater physiological reaction (Dmitrieva et al., 2013) or greater susceptibility to the detrimental effects of emotional distress (Hanson \& Chen, 2010). The non-significant association between NA and cortisol diurnal slope for the Control group may be explained by their perception of NA as non-threatening (Park et al., 2020).

The non-significant associations found for both the Vulnerable and the Resilient groups between PA and cortisol diurnal slope are not unique (Van Eck et al., 1996). However, the steeper cortisol diurnal slope at 
high PA for the Control group suggests that the riskier family backgrounds of the Vulnerable and Resilient groups may predispose them to less physiological responsivity to PA. It is also possible that the Control group experienced more high arousal PA linked to steeper cortisol diurnal slope while the Vulnerable and Resilient groups had more low arousal PA linked to no significant changes in cortisol diurnal slope (Hoyt et al., 2015). Nevertheless, these findings collectively suggest a unique pathway between resilience capacity and cortisol diurnal slope responses to negative vs positive emotions ( $\operatorname{Sin}$ et al., 2015). Further, there may be a difference in physiological sensitivity to affective valence between those from high and low risk families, such that the high risk Vulnerable and Resilient groups were more physiologically sensitive to demands and distress whereas the low risk Control group was more responsive to positive emotions.

Overall, the mostly similar cortisol diurnal patterns between the Vulnerable and the Resilient groups suggest that their common riskier early family backgrounds may be impacting on physiology more than current resilience capacity. This conjecture finds a basis in studies that proposed the programming of HPA-axis at sensitive early periods of development (Koss \& Gunnar, 2018). Additionally, the different cortisol diurnal slope changes to stress (i.e., demand) compared to NA (i.e., distress) support the need to look at these variables separately in future studies. Despite the groups not significantly differing in diurnal slope on average, meaningful differences emerged by stress and affect with the Control group showing opposite trends in cortisol diurnal slope responses when compared to their high risk Vulnerable and Resilient counterparts. These findings suggest that some of the conflicting results in cortisol research may be attributable to the lack of differentiation by resilience and family risk. Future cortisol studies may benefit from differentiating individuals by early risks and resilience capacity (Cicchetti \& Rogosch, 2007).

\section{Limitation and Strengths}

This study had limitations. Menstrual cycle phase among females (Kudielka et al., 2009) was not controlled. Despite carefully controlling for covariates that may impact stress and affect, we cannot rule out the influence of unmeasured aspects of the current psychosocial environment on cortisol outcomes such as quality of social contacts (Adam \& Gunnar, 2001). Moreover, cortisol levels only index part of physiological health (Juster et al., 2011) and are not a pure estimate of HPA-axis functioning (Hellhammer et al., 2009). As with most daily studies, missing data was inevitable. Although the participants were grouped into high and low-risk families, the overall family risk is still low. Further, the sample size of each group varied, and family risk was measured retrospectively. That said, findings suggest that the appraisal of early family life rather than objective occurrences impact outcomes more (Kaufman et al., 1997). Our findings are not generalizable to different age group individuals nor those from abusive, high-risk families.

This study also had strengths. The compliance rate in our study was higher than the $44-66 \%$ rate of other similarly designed daily studies $>7$ days (Heron et al., 2017). Also, we cross-checked reported saliva collection time against survey completion time and self-reported wake and sleep time, allowing higher confidence in our cortisol data accuracies (Kudielka et al., 2003). Reviews on salivary cortisol collection 
have emphasized maximizing compliance while maintaining low participant burden as priorities (Adam \& Kumari, 2009). We collected two saliva samples daily for 14 days, which should better characterize between-subject differences on cortisol slope (Segerstrom et al., 2014). Most prior studies collect more saliva samples across fewer days, some only on a single day (Van den Bergh et al., 2008). The EMA design helped reduce retrospective recall bias. Given that the definition of resilience necessitates the presence of adversity, we measured the resilience of our participants against a context of early family life risk and current transitory stress by studying emerging adults at a developmental transition who moved at least interstate often internationally for tertiary studies. Most studies measure resilience based on selfreport without the reporting of risks (Colich et al., 2020). We also categorized participants from low-risk families into the Control group as demographically similar comparisons. However, our results could be even more confidently stated if we had an additional comparison group with low family risk and high emotional distress.

\section{Conclusions, Future Directions, And Implications}

Our daily study showed that early family life, even at the lower spectrum of risk, exerted significant differences in cortisol diurnal slope outcomes when experiencing high stress and distress that were not attenuated by current resilience capacity. These modest but daily physiological differences may accumulatively amount to substantial health impact (Juster et al., 2018), which requires future exploration. Further, the interesting results from our exploratory hypotheses on affect are novel. These results should be replicated in future daily studies with a focus on examining the mechanisms and contextual factors (Shirtcliff et al., 2014) that explain these differences in cortisol diurnal slopes by stress and affect between individuals of differing resilience and family risks. This increased understanding can inform the development of effective interventions for people with early family risk, regardless of their current psychological adjustment (Shonkoff, 2012; Slopen et al., 2014).

\section{Declarations}

\section{AUTHOR CONTRIBUTIONS AND ACKNOWLEDGEMENTS:}

Material preparation, data collection, and analysis were performed by NT, YY, and JW. The first draft of the manuscript was written by NT and all authors commented on previous versions of the manuscript. All authors read and approved the final manuscript. We thank the participants who volunteered their time towards this study, and everyone who assisted with data collection.

\section{CONFLICTS OF INTEREST:}

All authors declare no conflict of interest. The funders had no role in the study design, data collection, analysis, interpretation, or presentation of results.

FUNDING: 
Wiley (1178487) and Bei (1140299) were supported by NHMRC fellowships.

\section{ETHICS APPROVAL:}

Monash University Human Research Ethics Committee (\#17281) approved the study.

CONSENT TO PARTICIPATE AND FOR PUBLICATION:

Flyer and explanatory statement including consent form https://doi.org/10.26180/14594001

CODE AVAILABILITY:

Analysis code [https://doi.org/10.26180/14703843] and research materials are available at [https://doi.org/10.26180/14593986.v1training and manuals] [https://doi.org/10.26180/14594238.v2 questionnaires].

DATA AVAILABILITY:

Data will be made available on reasonable request and is planned for public sharing as redacted dataset in the future.

\section{References}

1. Adam, E. K., \& Gunnar, M. R. (2001). Relationship functioning and home and work demands predict individual differences in diurnal cortisol patterns in women. Psychoneuroendocrinology, 26(2), 189208. https://doi.org/10.1016/S0306-4530(00)00045-7

2. Adam, E. K., Hawkley, L. C., Kudielka, B. M., \& Cacioppo, J. T. (2006). Day-to-day dynamics of experience-cortisol associations in a population-based sample of older adults. Proceedings of the National Academy of Sciences, 103(45), 17058-17063. https://doi.org/10.1073/pnas.0605053103

3. Adam, E. K., \& Kumari, M. (2009). Assessing salivary cortisol in large-scale, epidemiological research. Psychoneuroendocrinology, 34(10), 1423-1436. https://doi.org/10.1016/j.psyneuen.2009.06.011

4. Adam, E. K., Quinn, M. E., Tavernier, R., McQuillan, M. T., Dahlke, K. A., \& Gilbert, K.E. (2017). Diurnal cortisol slopes and mental and physical health outcomes: A systematic review and meta-analysis. Psychoneuroendocrinology, 83, 25-41. https://doi.org/10.1016/j.psyneuen.2017.05.018

5. Arnett, J. J. (2000). Emerging adulthood: A theory of development from the late teens through the twenties. American Psychologist, 55(5), 469-480. https://doi.org/10.1037//0003-066X.55.5.469

6. Balters, S., Geeseman, J. W., Tveten, A. K., Hildre, H. P., Ju, W., \& Steinert, M. (2020). Mayday, Mayday, Mayday: Using salivary cortisol to detect distress (and eustress!) in critical incident training. International Journal of Industrial Ergonomics, 78, 102975. https://doi.org/10.1016/j.ergon.2020.102975

7. Bernard, K., Zwerling, J., \& Dozier, M. (2015). Effects of early adversity on young children's diurnal cortisol rhythms and externalizing behavior. Developmental Psychobiology, 57(8), 935-947. 
https://doi.org/10.1002/dev.21324

8. Brody, G. H., Yu, T., Chen, E., Miller, G. E., Kogan, S. M., \& Beach, S. R. (2013). Is resilience only skin deep? Rural African Americans' socioeconomic status-related risk and competence in preadolescence and psychological adjustment and allostatic load at age 19. Psychological Science, 24(7), 1285-1293. https://doi.org/10.1177/0956797612471954

9. Buhler-Wassmann, A. C., Hibel, L. C., Fondren, K., \& Valentino, K. (2020). Child diurnal cortisol differs based on profiles of maternal emotion socialization in high risk, low income, and racially diverse families. Developmental Psychobiology, 63(3), 538-555 https://doi.org /10.1002/dev.22048

10. Carlson, M., \& Earls, F. (1997). Psychological and neuroendocrinological sequelae of early social deprivation in institutionalized children in Romania. Annals of the New York Academy of Sciences, 807(1), 419-428. https://doi.org/10.1111/j.1749-6632.1997.tb51936.x

11. Cella, D., Riley, W., Stone, A., Rothrock, N., Reeve, B., Yount, S., Amtmann, D., Bode, R., Buysse, D., Choi, S., Cook, K., DeVellis, R., DeWalt, D., Fries, J. F., Gershon, R., Hahn, E. A., Lai, J.-S., Pilkonis, P., Revicki, D., ... Hays, R. (2010). The Patient-Reported Outcomes Measurement Information System (PROMIS) developed and tested its first wave of adult self-reported health outcome item banks: 2005-2008. Journal of Clinical Epidemiology, 63(11), 1179-1194. https://doi.org/10.1016/j.jclinepi.2010.04.011

12. Chen, C. X., Kroenke, K., Stump, T. E., Kean, J., Carpenter, J. S., Krebs, E. E., ... \& Monahan, P. O. (2018). Estimating minimally important differences for the PROMIS $®$ Pain Interference Scales: results from three randomized clinical trials. Pain, 159(4), 775. doi: 10.1097/j.pain.0000000000001121

13. Chi, P., Slatcher, R. B., Li, X., Zhao, J., Zhao, G., Ren, X., ... \& Stanton, B. (2015). Perceived stigmatization, resilience, and diurnal cortisol rhythm among children of parents living with HIV. Psychological Science, 26(6), 843-852. https://doi.org/10.1177/0956797615572904

14. Cicchetti, D., \& Rogosch, F. A. (2007). Personality, adrenal steroid hormones, and resilience in maltreated children: A multi-level perspective. Development and Psychopathology, 19(3), 787-809. https://doi.org/10.1017/S0954579407000399

15. Colich, N. L., Sheridan, M. A., Humphreys, K. L., Wade, M., Tibu, F., Nelson, C. A., Zeanah, C. H., Fox, N. A., \& McLaughlin, K. A. (2020). Heightened sensitivity to the caregiving environment during adolescence: Implications for recovery following early-life adversity. Journal of Child Psychology and Psychiatry, n/a(n/a). https://doi.org/10.1111/jcpp.13347

16. Deer, L. K., Shields, G. S., Ivory, S. L., Hostinar, C. E., \& Telzer, E. H. (2018). Racial/ethnic disparities in cortisol diurnal patterns and affect in adolescence. Development and Psychopathology, 30(5), 1977. doi: 10.1017/S0954579418001098

17. DeSantis, A. S., Adam, E. K., Doane, L. D., Mineka, S., Zinbarg, R. E., \& Craske, M. G. (2007). Racial/ethnic differences in cortisol diurnal rhythms in a community sample of adolescents. Journal of Adolescent Health, 41(1), 3-13. https://doi.org/10.1016/j.jadohealth.2007.03.006

18. Dmitrieva, N. O., Almeida, D. M., Dmitrieva, J., Loken, E., \& Pieper, C. F. (2013). A day- centered approach to modeling cortisol: diurnal cortisol profiles and their associations among US adults. Psychoneuroendocrinology, 38(10), 2354-2365. https://doi.org/10.1016/j.psyneuen.2013.05.003 
19. Doane, L. D., \& Adam, E. K. (2010). Loneliness and cortisol: Momentary, day-to-day, and trait associations. Psychoneuroendocrinology, 35(3), 430-441.

https://doi.org/10.1016/j.psyneuen.2009.08.005

20. DiCorcia, J. A., Sravish, A. V., \& Tronick, E. (2013). The Everyday Stress Resilience hypothesis: Unfolding resilience from a perspective of everyday stress and coping. In G. Laviola \& S. Macrì (Eds.), Adaptive and Maladaptive Aspects of Developmental Stress (pp. 67-93). Springer. https://doi.org/10.1007/978-1-4614-5605-6_4

21. Faul, F., Erdfelder, E., Lang, A. G., \& Buchner, A. (2007). G* Power 3: A flexible statistical power analysis program for the social, behavioral, and biomedical sciences. Behavior Research Methods, 39(2), 175-191. https://doi.org/10.3758/BF03193146

22. Felitti, V. J., Anda, R. F., Nordenberg, D., Williamson, D. F., Spitz, A. M., Edwards, V., Koss, M. P., \& Marks, J. S. (1998). Relationship of childhood abuse and household dysfunction to many of the leading causes of death in adults. American Journal of Preventive Medicine, 14(4), 245258. https://doi.org/10.1016/S0749-3797(98)00017-8

23. Gunnar, M. R., \& Vazquez, D. M. (2001). Low cortisol and a flattening of expected daytime rhythm: Potential indices of risk in human development. Development and Psychopathology, 13(3), 515538. doi: 10.1017/S0954579401003066

24. Hanson, M. D., \& Chen, E. (2010). Daily stress, cortisol, and sleep: The moderating role of childhood psychosocial environments. Health Psychology, 29(4), 394-402. https://doi.org/10.1037/a0019879

25. Hellhammer, D. H., Wüst, S., \& Kudielka, B. M. (2009). Salivary cortisol as a biomarker in stress research. Psychoneuroendocrinology, 34(2), 163-171.

https://doi.org/10.1016/j.psyneuen.2008.10.026

26. Heron, K. E., Everhart, R. S., McHale, S. M., \& Smyth, J. M. (2017). Using mobile-technology-based Ecological Momentary Assessment (EMA) methods with youth: A systematic review and recommendations. Journal of Pediatric Psychology, 42(10), 1087-1107. https://doi.org/10.1093/jpepsy/jsx078

27. Hoyt, L. T., Craske, M. G., Mineka, S., \& Adam, E. K. (2015). Positive and negative affect and arousal: Cross-sectional and longitudinal associations with adolescent cortisol diurnal rhythms. Psychosomatic Medicine, 77(4), 392-401. https://doi.org/10.1097/PSY.0000000000000178

28. Jacobs N, Myin-Germeys I, Derom C, Delespaul P, van Os J, Nicolson NA (2007). A momentary assessment study of the relationship between affective and adrenocortical stress responses in daily life. Biological Psychology,74 (1):60-66.10.1016/j.biopsycho.2006.07.002

29. Juster, R. P., Bizik, G., Picard, M., Arsenault-Lapierre, G., Sindi, S., Trepanier, L., ... \& Lupien, S. J. (2011). A transdisciplinary perspective of chronic stress in relation to psychopathology throughout life span development. Development and Psychopathology, 23(3), 725-776. doi:10.1017/S0954579411000289

30. Juster, R. P., Sasseville, M., Giguère, C. É., Lupien, S. J., \& Signature Consortium. (2018). Elevated allostatic load in individuals presenting at psychiatric emergency services. Journal of 
Psychosomatic Research, 115, 101-109. https://doi.org/10.1016/j.jpsychores.2018.10.012

31. Kaufman, J., Birmaher, B., Perel, J., Dahl, R. E., Moreci, P., Nelson, B., ... \& Ryan, N. D. (1997). The corticotropin-releasing hormone challenge in depressed abused, depressed nonabused, and normal control children. Biological Psychiatry, 42(8), 669-679. https://doi.org/10.1016/S00063223(96)00470-2

32. Khawaja, N., \& Dempsey, J. (2008). A comparison of international and domestic tertiary students in Australia. Journal of Psychologists and Counsellors in Schools, 18(1), 30-46. doi: 10.1375/ajgc.18.1.30

33. Klein, L. C., Kim, K., Almeida, D. M., Femia, E. E., Rovine, M. J., \& Zarit, S. H. (2016). Anticipating an easier day: Effects of adult day services on daily cortisol and stress. The Gerontologist, 56(2), 303312. https://doi.org/10.1093/geront/gnu060

34. Kliewer, W., Reid-Quiñones, K., Shields, B. J., \& Foutz, L. (2009). Multiple risks, emotion regulation skill, and cortisol in low-income African American youth: A prospective study. Journal of Black Psychology, 35(1), 24-43. https://doi.org/10.1177/0095798408323355

35. Koss, K. J., \& Gunnar, M. R. (2018). Annual research review: Early adversity, the hypothalamicpituitary-adrenocortical axis, and child psychopathology. Journal of Child Psychology and Psychiatry, 59(4), 327-346. https://doi.org /10.1111/jcpp.12784

36. Kudielka, B. M., Broderick, J. E., \& Kirschbaum, C. (2003). Compliance with saliva sampling protocols: Electronic monitoring reveals invalid cortisol daytime profiles in noncompliant subjects. Psychosomatic Medicine, 65(2), 313-319. https://doi.org/10.1097/01.psy.0000058374.50240.bf

37. Kudielka, B. M., Hellhammer, D. H., \& Wüst, S. (2009). Why do we respond so differently? Reviewing determinants of human salivary cortisol responses to challenge. Psychoneuroendocrinology, 34(1), 2-18. https://doi.org/10.1016/j.psyneuen.2008.10.004

38. Lai, J. C. L., Leung, M. O. Y., Lee, D. Y. H., Lam, Y. W., \& Berning, K. (2020). Biomarking trait resilience with salivary cortisol in Chinese undergraduates. Frontiers in Psychology, 11. https://doi.org/10.3389/fpsyg.2020.536510

39. Lehrer, H. M., Steinhardt, M. A., Dubois, S. K., \& Laudenslager, M. L. (2020). Perceived stress, psychological resilience, hair cortisol concentration, and metabolic syndrome severity: A moderated mediation model. Psychoneuroendocrinology, 113, 104510. https://doi.org/10.1016/j.psyneuen.2019.104510

40. Liao, Y., Skelton, K., Dunton, G., \& Bruening, M. (2016). A systematic review of methods and procedures used in ecological momentary assessments of diet and physical activity research in youth: an adapted STROBE checklist for reporting EMA studies (CREMAS). Journal of Medical Internet Research, 18(6), e151. doi:10.2196/jmir.4954

41. Marchand, A., Durand, P., Juster, R. P., \& Lupien, S. J. (2014). Workers' psychological distress, depression, and burnout symptoms: associations with diurnal cortisol profiles. Scandinavian Journal of Work, Environment \& Health, 305-314. doi:10.5271/sjweh.3417 
42. Martin, C. G., Kim, H. K., Bruce, J., \& Fisher, P. A. (2014). Child diurnal cortisol rhythms, parenting quality, and externalizing behaviors in preadolescence. Psychoneuroendocrinology, 40, 170-180. https://doi.org/10.1016/j.psyneuen.2013.11.015

43. McLachlan, K., Rasmussen, C., Oberlander, T. F., Loock, C., Pei, J., Andrew, G., Reynolds, J., \& Weinberg, J. (2016). Dysregulation of the cortisol diurnal rhythm following prenatal alcohol exposure and early life adversity. Alcohol, 53, 9-18. https://doi.org/10.1016/j.alcohol.2016.03.003

44. Merz, E. L., \& Roesch, S. C. (2011). Modeling trait and state variation using multilevel factor analysis with PANAS daily diary data. Journal of Research in Personality, 45(1), 2-9. https://doi.org/10.1016/j.jrp.2010.11.003

45. Mikolajczak, M., Roy, E., Luminet, O., \& De Timary, P. (2008). Resilience and hypothalamic-pituitaryadrenal axis reactivity under acute stress in young men. Stress, 11(6), 477482. https://doi.org/10.1080/10253890701850262

46. Miller, G. E., Chen, E., \& Zhou, E. S. (2007). If it goes up, must it come down? Chronic stress and the hypothalamic-pituitary adrenocortical axis in humans. Psychological Bulletin, 133(1), 25-45. https://doi.org/10.1037/0033-2909.133.1.25

47. Miller, K. G., Wright, A. G., Peterson, L. M., Kamarck, T. W., Anderson, B. A., Kirschbaum, C., ... \& Manuck, S. B. (2016). Trait positive and negative emotionality differentially associate with diurnal cortisol activity. Psychoneuroendocrinology, 68, 177-185.

https://doi.org/10.1016/j.psyneuen.2016.03.004

48. Nicolson, N. A. (1992). Stress, coping and cortisol dynamics in daily life. The experience of psychopathology: Investigating mental disorders in their natural settings, 219-232.

49. O'Connor, D. B., Branley-Bell, D., Green, J. A., Ferguson, E., O'Carroll, R. E., \& O'Connor, R. C. (2020). Effects of childhood trauma, daily stress, and emotions on daily cortisol levels in individuals vulnerable to suicide. Journal of Abnormal Psychology, 129(1), 92. https://doi.org/10.1037/abn0000482

50. Ong, A. D., Ong, A. D., Bergeman, C. S., Bisconti, T. L., \& Wallace, K. A. (2016). Psychological resilience, positive emotions, and successful adaptation to stress in later life. Journal of Personality and Social Psychology, 91(4), 730. https://doi.org/10.1037/0022-3514.91.4.730

51. Park, J., Kitayama, S., Miyamoto, Y., \& Coe, C. L. (2020). Feeling bad is not always unhealthy: Culture moderates the link between negative affect and diurnal cortisol profiles. Emotion, 20(5), 721. https://doi.org/10.1037/emo0000605

52. R Core Team (2019). R: A language and environment for statistical computing. R Foundation for Statistical Computing, Vienna, Austria. URL https://www.R-project.org/.

53. Ross, K. M., Murphy, M. L., Adam, E. K., Chen, E., \& Miller, G. E. (2014). How stable are diurnal cortisol activity indices in healthy individuals? Evidence from three multi-wave studies.

Psychoneuroendocrinology, 39, 184-193. https://doi.org/10.1016/j.psyneuen.2013.09.016

54. Segerstrom, S. C., Boggero, I. A., Smith, G. T., \& Sephton, S. E. (2014). Variability and reliability of diurnal cortisol in younger and older adults: Implications for design decisions. 
Psychoneuroendocrinology, 49, 299-09. https://doi.org/10.1016/j.psyneuen.2014.07.022

55. Selye, H. (1976). Stress without distress. In Psychopathology of Human Adaptation (pp. 137-146). Springer, Boston, MA.

56. Shin, I. Y., Ahn, R. S., Chun, S. I., Lee, Y. J., Kim, M. S., Lee, C. K., \& Sung, S. (2011). Cortisol awakening response and nighttime salivary cortisol levels in healthy working Korean subjects. Yonsei Medical Journal, 52(3), 435. doi:10.3349/ymj.2011.52.3.435

57. Shirtcliff, E. A., Peres, J. C., Dismukes, A. R., Lee, Y., \& Phan, J. M. (2014). Hormones: Commentary: Riding the physiological roller coaster: Adaptive significance of cortisol stress reactivity to social contexts. Journal of Personality Disorders, 28(1), 40-51. https://doi.org/10.1521/pedi.2014.28.1.40

58. Shonkoff, J. P. (2012). Leveraging the biology of adversity to address the roots of disparities in health and development. Proceedings of the National Academy of Sciences of the United States of America, 109(Suppl 2), 17302-17307. https://doi.org/10.1073/pnas.1121259109

59. Sin, N. L., Ong, A. D., Stawski, R. S., \& Almeida, D. M. (2017). Daily positive events and diurnal cortisol rhythms: Examination of between-person differences and within-person variation.

Psychoneuroendocrinology, 83, 91-100. https://doi.org/10.1016/j.psyneuen.2017.06.001

60. Sladek, M. R., Doane, L. D., Luecken, L. J., \& Eisenberg, N. (2016). Perceived stress, coping, and cortisol reactivity in daily life: A study of adolescents during the first year of college. Biological Psychology, 117, 8-15. https://doi.org/10.1016/j.biopsycho.2016.02.003

61. Slopen, N., McLaughlin, K. A., \& Shonkoff, J. P. (2014). Interventions to improve cortisol regulation in children: A systematic review.. Pediatrics, 133(2), 312-326. https://doi.org/10.1542/peds.2013-1632

62. Smith, B. W., Dalen, J., Wiggins, K., Tooley, E., Christopher, P., \& Bernard, J. (2008). The brief resilience scale: assessing the ability to bounce back. International Journal of Behavioral Medicine, 15(3), 194200. https://doi.org/10.1080/10705500802222972

63. Smyth, J. M., Ockenfels, M. C., Gorin, A. A., Catley, D., Porter, L. S., Kirschbaum, C., ... \& Stone, A. A. (1998). Individual differences in the diurnal cycle of cortisol. Psychoneuroendocrinology, 22(2), 89105. https://doi.org/10.1016/S0306-4530(96)00039-X

64. Stawski, R. S., Cichy, K. E., Piazza, J. R., \& Almeida, D. M. (2013). Associations among daily stressors and salivary cortisol: Findings from the National Study of Daily Experiences.

Psychoneuroendocrinology, 38(11), 2654-2665. https://doi.org/10.1016/j.psyneuen.2013.06.023

65. Tomyn, A. J., \& Weinberg, M. K. (2018). Resilience and subjective wellbeing: A psychometric evaluation in young Australian adults. Australian Psychologist, 53(1), 68-76. https://doi.org /10.1111/ap.12251

66. Wang, A. W., \& Hoyt, M. A. (2018). Benefit finding and diurnal cortisol after prostate cancer: The mediating role of positive affect. Psycho-oncology, 27(4), 1200-

1205.https://doi.org/10.1002/pon.4647

67. Watson, D., \& Clark, L. A. (1998). The PANAS-X: Manual for the Positive and Negative Affect Schedule -Expanded Form. 28. 
68. Watson, D., \& Pennebaker, J. W. (1989). Health complaints, stress, and distress: exploring the central role of negative affectivity. Psychological Review, 96(2), 234. https://doi.org/10.1037/0033295X.96.2.234

69. Werner, E. E. (1993). Risk, resilience, and recovery: Perspectives from the Kauai longitudinal study. Development and Psychopathology, 5(4), 503-515. https://doi.org/10.1017/S095457940000612X

70. Wong, J. D., Seltzer, M. M., Greenberg, J. S., Hong, J., Almeida, D. M., \& Coe, C. L. (2012). Stressful life events and daily stressors affect awakening cortisol level in midlife mothers of individuals with autism spectrum disorders. Aging \& Mental Health, 16(8), 939-949. https://doi.org/10.1080/13607863.2012.688191

71. Van den Bergh, B. R. H., Van Calster, B., Pinna Puissant, S., \& Van Huffel, S. (2008). Self-reported symptoms of depressed mood, trait anxiety and aggressive behavior in post-pubertal adolescents: Associations with diurnal cortisol profiles. Hormones and Behavior, 54(2), 253-257. https://doi.org/10.1016/j.yhbeh.2008.03.015

72. Van Eck, M., Berkhof, H., Nicolson, N., \& Sulon, J. (1996). The effects of perceived stress, traits, mood states, and stressful daily events on salivary cortisol. Psychosomatic Medicine, 58(5), 447-458. 10.1097/00006842-199609000-00007

73. Von Elm, E., Altman, D. G., Egger, M., \& Pocock, S. J. (2008). Gøtzsche PC, Vandenbroucke JP: The Strengthening the Reporting of Observational Studies in Epidemiology (STROBE) statement: guidelines for reporting observational studies. Journal of Clinical Epidemiology, 61(4), 344-349. https://doi.org/10.1016/j.ijsu.2014.07.014

\section{Tables}


Table 1

Descriptive Statistics for Demographic and Daily Variables $(\mathrm{N}=95)$ by Groups

\begin{tabular}{|c|c|c|c|c|}
\hline Variables & $\begin{array}{l}\text { Overall } \\
(N=98)\end{array}$ & $\begin{array}{l}\text { Control } \\
(N=45)\end{array}$ & $\begin{array}{l}\text { Resilient } \\
(N=19)\end{array}$ & $\begin{array}{l}\text { Vulnerable } \\
(N=34)\end{array}$ \\
\hline \multicolumn{5}{|l|}{ Demographic Variables } \\
\hline Age (years) & $20.48(1.59)$ & $\begin{array}{l}20.39 \\
(1.62)\end{array}$ & $\begin{array}{l}20.24 \\
(1.40)\end{array}$ & $\begin{array}{l}20.73 \\
(1.66)\end{array}$ \\
\hline Female (vs Male) & $75(78.9 \%)$ & $\begin{array}{l}33 \\
(76.7 \%)\end{array}$ & $\begin{array}{l}13 \\
(72.2 \%)\end{array}$ & $\begin{array}{l}29 \\
(85.3 \%)\end{array}$ \\
\hline Single (vs In Relationship) & $70(73.7 \%)$ & $\begin{array}{l}32 \\
(74.4 \%)\end{array}$ & $\begin{array}{l}11 \\
(61.1 \%)\end{array}$ & $\begin{array}{l}27 \\
(79.4 \%)\end{array}$ \\
\hline Subjective Socioeconomic Status $(1-10)$ & $5.56(1.45)$ & $\begin{array}{l}5.72 \\
(1.44)\end{array}$ & $\begin{array}{l}5.72 \\
(1.27)\end{array}$ & $\begin{array}{l}5.26 \\
(1.54)\end{array}$ \\
\hline \multicolumn{5}{|l|}{ Race/Ethnicity ${ }^{+}$} \\
\hline South Asian & $13(13.7 \%)$ & $3(7.0 \%$ & $4(22.2 \%)$ & $1(2.9 \%)$ \\
\hline Southeast Asian & $44(46.3 \%)$ & $\begin{array}{l}19 \\
(44.2 \%)\end{array}$ & $\begin{array}{l}10 \\
(55.6 \%)\end{array}$ & $\begin{array}{l}15 \\
(44.1 \%)\end{array}$ \\
\hline East Asian & $23(24.2 \%)$ & $\begin{array}{l}14 \\
(32.6 \%)\end{array}$ & $1(5.6 \%)$ & $1(2.9 \%)$ \\
\hline White/European/Anglo-Celtic & $8(8.4 \%)$ & $4(9.3 \%)$ & $2(11.1 \%)$ & $8(23.5 \%)$ \\
\hline Others & $7(7.4 \%)$ & $3(7.0 \%)$ & $1(5.6 \%)$ & $6(17.6 \%)$ \\
\hline \multicolumn{5}{|l|}{ Nationality } \\
\hline International (vs Interstate) & $88(92.6 \%)$ & $\begin{array}{l}41 \\
(95.3 \%)\end{array}$ & $\begin{array}{l}15 \\
(83.3 \%)\end{array}$ & $\begin{array}{l}32 \\
(94.1 \%)\end{array}$ \\
\hline Time Spent in Melbourne (years) & $0.73(0.95)$ & $\begin{array}{l}0.64 \\
(0.85)\end{array}$ & $\begin{array}{l}0.38 \\
(0.52)^{\vee}\end{array}$ & $\begin{array}{l}1.02 \\
(1.16)^{R}\end{array}$ \\
\hline First-time leaving home (Yes or No) & $68(71.6 \%)$ & $\begin{array}{l}30 \\
(69.8 \%)\end{array}$ & $\begin{array}{l}11 \\
(61.1 \%)\end{array}$ & $\begin{array}{l}27 \\
(79.4 \%)\end{array}$ \\
\hline English Language Acculturation (1-5) & $3.82(1.02)$ & $\begin{array}{l}3.35 \\
(1.05)^{R V}\end{array}$ & $\begin{array}{l}4.66 \\
(0.53)^{C V}\end{array}$ & $\begin{array}{l}3.97 \\
(0.86)^{C R}\end{array}$ \\
\hline $\begin{array}{l}\text { Non-English Native Speaker (vs English } \\
\text { Native Speaker) }\end{array}$ & $65(68.4 \%)$ & $\begin{array}{l}35 \\
(81.4 \%)^{R}\end{array}$ & $\begin{array}{l}6 \\
(33.3 \%)^{c V}\end{array}$ & $\begin{array}{l}24 \\
(70.6 \%)^{R}\end{array}$ \\
\hline Full-time student (vs Part-time) & $93(97.9 \%)$ & $\begin{array}{l}41 \\
(95.3 \%)\end{array}$ & $\begin{array}{l}18 \\
(100.0 \%)\end{array}$ & $\begin{array}{l}34 \\
(100.0 \%)\end{array}$ \\
\hline Employed (vs Unemployed) & $20(21.0 \%)$ & $8(18.6 \%)$ & $4(22.3 \%)$ & $8(23.5 \%)$ \\
\hline
\end{tabular}




\begin{tabular}{|c|c|c|c|c|}
\hline $\begin{array}{l}\text { Co-parented upbringing (vs Single-parented } \\
\text { upbringing) }\end{array}$ & $88(92.6 \%)$ & $\begin{array}{l}40 \\
(93.0 \%)\end{array}$ & $\begin{array}{l}16 \\
(88.9 \%)\end{array}$ & $\begin{array}{l}32 \\
(94.1 \%)\end{array}$ \\
\hline Family Risk (13-65) & $27.07(8.66)$ & $\begin{array}{l}18.79 \\
(1.73)^{R V}\end{array}$ & $\begin{array}{l}34.39 \\
(5.16)^{C}\end{array}$ & $\begin{array}{l}33.68 \\
(5.70)^{\mathrm{C}}\end{array}$ \\
\hline Resilience (1-5) & $3.19(0.76)$ & $\begin{array}{l}3.50 \\
(0.55)^{R V}\end{array}$ & $\begin{array}{l}3.94 \\
(0.23)^{\mathrm{CV}}\end{array}$ & $\begin{array}{l}2.40 \\
(0.43)^{C R}\end{array}$ \\
\hline Anxiety symptoms (T-Score) & $56.07(9.09)$ & $\begin{array}{l}51.49 \\
(4.29)^{\vee}\end{array}$ & $\begin{array}{l}52.28 \\
(8.76)^{\vee}\end{array}$ & $\begin{array}{l}63.87 \\
(8.63)^{\mathrm{CR}}\end{array}$ \\
\hline Depressive symptoms (T-Score) & $52.75(9.24)$ & $\begin{array}{l}49.04 \\
(6.73)^{\vee}\end{array}$ & $\begin{array}{l}48.09 \\
(5.09)^{v}\end{array}$ & $\begin{array}{l}59.92 \\
(9.98)^{C R}\end{array}$ \\
\hline Stress at Baseline (0-56) & $25.45(7.78)$ & $\begin{array}{l}21.51 \\
(6.73)^{\vee}\end{array}$ & $\begin{array}{l}24.00 \\
(4.39)^{\mathrm{V}}\end{array}$ & $\begin{array}{l}31.21 \\
(7.01)^{C R}\end{array}$ \\
\hline $\begin{array}{l}\text { Pre-COVID-19 period (vs during COVID-19 } \\
\text { period) }\end{array}$ & $69(72.6 \%)$ & $\begin{array}{l}32 \\
(74.4 \%)\end{array}$ & $\begin{array}{l}13 \\
(72.2 \%)\end{array}$ & $\begin{array}{l}24 \\
(70.6 \%)\end{array}$ \\
\hline Daily Variables & & ICC & & \\
\hline
\end{tabular}

Perceived Stress levels (range 0 - 10)

\begin{tabular}{|lcc|} 
Morning, No. Obs. $=937$ & $1.39(1.97)$ & $.39(61 \%)$ \\
\hline Pre-sleep, No. Obs. $=1279$ & $2.41(2.46)$ & $.39(61 \%)$ \\
\hline Negative Affect levels $($ range $1-5)$ & & \\
\hline Morning, No. Obs. $=936$ & $1.36(0.55)$ & $.61(39 \%)$ \\
\hline Pre-sleep, No. Obs. $=1275$ & $1.49(0.70)$ & $.61(39 \%)$ \\
\hline Positive Affect levels (range $1-5)$ & & \\
Morning, No. Obs. $=936$ & $2.65(1.01)$ & $.65(35 \%)$ \\
\hline Pre-sleep, No. Obs. $=1279$ & $2.63(1.01)$ & $.61(39 \%)$ \\
\hline Cortisol levels (nmol/L) & & \\
\hline Morning, No. Obs. $=1142$ & $11.32(14.68)$ & $.23(77 \%)$ \\
\hline Pre-sleep, No. Obs. = 1203 & $1.29(1.93)$ & $.34(66 \%)$ \\
\hline
\end{tabular}

Note. ICC = Intraclass Correlations. No. of Obs = Number of observations. Results are M (SD) for continuous variables and $\mathrm{N}(\%)$ for categorical ones. Ranges in parentheses are the possible range of a scale. Superscript $\mathrm{V}, \mathrm{R}$, and $\mathrm{C}$ represent significant differences with the marked group. ${ }^{+}$Chi-square test was used to examine significant differences in race by group and revealed no significant differences ( $p=$ .19) 
Table 2

2-Way Diurnal Cortisol Slope x Stress/Affect/Group Interactions and Simple Slopes

\begin{tabular}{|c|c|c|c|c|}
\hline & Stress & $\begin{array}{l}\text { Negative } \\
\text { Affect }\end{array}$ & $\begin{array}{l}\text { Positive } \\
\text { Affect }\end{array}$ & Group \\
\hline \multicolumn{5}{|l|}{$\begin{array}{l}\text { 2-way Interaction: } \\
\text { Diurnal Cortisol Slope x }\end{array}$} \\
\hline \multirow[t]{2}{*}{ Variable } & $-0.05, p=.23$ & $0.20, p=.065$ & $-0.09, p=.046$ & - \\
\hline & {$[-0.12,0.03]$} & {$[-0.003,0.42]$} & {$[-0.17,-0.004]$} & \\
\hline \multirow[t]{2}{*}{ Vulnerable vs Control } & - & - & - & $-0.13, p=0.14$ \\
\hline & & & & {$[-0.30,0.04]$} \\
\hline \multirow[t]{2}{*}{ Vulnerable vs Resilient } & - & - & - & $-0.11, p=0.27$ \\
\hline & & & & {$[-0.30,0.08]$} \\
\hline \multirow[t]{2}{*}{ Resilient vs Control } & - & - & - & $-0.02, p=0.80$ \\
\hline & & & & {$[-0.19,0.15]$} \\
\hline \multicolumn{5}{|l|}{ Simple Diurnal Slopes } \\
\hline \multirow{2}{*}{ Low ( $10^{\text {th }}$ Percentile) } & $-2.37, p<.001$ & $-2.51, p<.001$ & $-2.35, p<.001$ & - \\
\hline & {$[-2.50,-2.23]$} & {$[-2.62,-2.41]$} & {$[-2.46,-2.24]$} & \\
\hline \multirow[t]{2}{*}{ High ( $90^{\text {th }}$ Percentile) } & $-2.56, p<.001$ & $-2.29, p<.001$ & $-2.51, p<.001$ & - \\
\hline & {$[-2.78,-2.35]$} & {$[-2.46,-2.13]$} & {$[-2.62,-2.41]$} & \\
\hline \multirow[t]{2}{*}{ Control } & - & - & - & $-2.39, p<.001$ \\
\hline & & & & {$[-2.49,-2.28]$} \\
\hline \multirow[t]{2}{*}{ Resilient } & - & - & - & $-2.41, p<.001$ \\
\hline & & & & {$[-2.55,-2.27]$} \\
\hline \multirow[t]{2}{*}{ Vulnerable } & - & - & - & $-2.52, p<.001$ \\
\hline & & & & {$[-2.64,-2.39]$} \\
\hline
\end{tabular}

Note. Bold highlights $p<.05$. Estimates are unstandardized regression coefficients for interactions or simple slopes, followed by $p$-values, and $95 \%$ confidence intervals. All estimates are from linear mixed models with all covariates included. 
Table 3

3-Way Diurnal Cortisol Slope x Group x Stress/Affect Interactions and Simple Slopes

\begin{tabular}{|c|c|c|c|}
\hline & Stress & $\begin{array}{l}\text { Negative } \\
\text { Affect }\end{array}$ & $\begin{array}{l}\text { Positive } \\
\text { Affect }\end{array}$ \\
\hline \multicolumn{4}{|l|}{$\begin{array}{l}\text { 3-way Interactions } \\
\text { Diurnal x Group x Variable }\end{array}$} \\
\hline \multirow[t]{2}{*}{ The Vulnerable vs The Control } & $-0.29, p<.001$ & $0.73, p=.020$ & $0.20, p=.061$ \\
\hline & {$[-0.47,-0.13]$} & {$[0.15,1.36]$} & {$[-0.01,0.39]$} \\
\hline \multirow[t]{2}{*}{ The Vulnerable vs The Resilient } & $0.30, p=.10$ & $-1.18, p=.029$ & $0.03, p=.87$ \\
\hline & {$[-0.07,0.65]$} & {$[-2.21,-0.10]$} & {$[-0.32,0.37]$} \\
\hline \multirow[t]{2}{*}{ The Resilient vs The Control } & $-0.59, p=.002$ & $1.91, p=.002$ & $0.17, p=.30$ \\
\hline & {$[-0.96,-0.21]$} & {$[0.74,3.08]$} & {$[-0.15,0.48]$} \\
\hline \multicolumn{4}{|l|}{$\begin{array}{l}\text { Simple 2-Way Interactions } \\
\text { (Diurnal x Variable) by Group }\end{array}$} \\
\hline \multirow[t]{2}{*}{ The Control } & $0.20, p=.006$ & $-0.45, p=.11$ & $-0.16, p=.003$ \\
\hline & {$[0.06,0.34]$} & {$[-1.02,0.09]$} & {$[-0.26,-0.06]$} \\
\hline \multirow[t]{2}{*}{ The Resilient } & $-0.39, p=.027$ & $1.46, p=.006$ & $0.009, p=.95$ \\
\hline & {$[-0.74,-0.04]$} & {$[0.41,2.47]$} & {$[-0.29,0.30]$} \\
\hline \multirow[t]{2}{*}{ The Vulnerable } & $-0.09, p=.043$ & $0.27, p=.032$ & $0.037, p=.68$ \\
\hline & {$[-0.19,-0.01]$} & {$[0.04,0.53]$} & {$[-0.14,0.21]$} \\
\hline \multicolumn{4}{|l|}{ Simple Diurnal Slopes } \\
\hline \multicolumn{4}{|l|}{ Low Variable Levels } \\
\hline \multirow[t]{2}{*}{ The Control } & \multirow{2}{*}{$\begin{array}{c}-2.61, p<.001 \\
{[-2.83,-2.40]}\end{array}$} & $-2.13, p<.001$ & $-2.14, p<.001$ \\
\hline & & {$[-2.35,-1.91]$} & {$[-2.31,-1.96]$} \\
\hline \multirow[t]{2}{*}{ The Resilient } & \multirow{2}{*}{$\begin{array}{c}-1.77, p<.001 \\
{[-2.35,-1.19]}\end{array}$} & $-2.94, p<.001$ & $-2.40, p<.001$ \\
\hline & & {$[-3.32,-2.56]$} & {$[-2.75,-2.04]$} \\
\hline \multirow[t]{2}{*}{ The Vulnerable } & \multirow{2}{*}{$\begin{array}{c}-2.30, p<.001 \\
{[-2.52,-2.08]}\end{array}$} & $-2.55, p<.001$ & $-2.48, p<.001$ \\
\hline & & {$[-2.72,-2.38]$} & {$[-2.67,-2.30]$} \\
\hline \multicolumn{4}{|l|}{ High Variable Levels } \\
\hline \multirow[t]{2}{*}{ The Control } & \multirow{2}{*}{$\begin{array}{c}-1.76, p<.001 \\
{[-2.21,-1.30]}\end{array}$} & $-2.62, p<.001$ & $-2.44, p<.001$ \\
\hline & & {$[-3.07,-2.17]$} & {$[-2.61,-2.28]$} \\
\hline The Resilient & $\begin{array}{c}-3.46, p<.001 \\
\text { Page } 23 / 27\end{array}$ & $-1.36, p<.001$ & $-2.38, p<.001$ \\
\hline
\end{tabular}




\begin{tabular}{|llll|} 
& {$[-4.42,-2.50]$} & {$[-2.15,-0.57]$} & {$[-2.67,-2.08]$} \\
\hline The Vulnerable & $-2.70, p<.001$ & $-2.25, p<.001$ & $-2.41, p<.001$ \\
& {$[-2.95,-2.45]$} & {$[-2.47,-2.04]$} & {$[-2.65,-2.17]$} \\
\hline
\end{tabular}

Note. Bold highlights $p<.05$. Variable in the table varies by column and is either stress, negative affect, or positive affect. Estimates are unstandardized regression coefficients for interactions or simple slopes, followed by $p$-values, and $95 \%$ confidence intervals. All estimates are from linear mixed models with all covariates included.

\section{Figures}

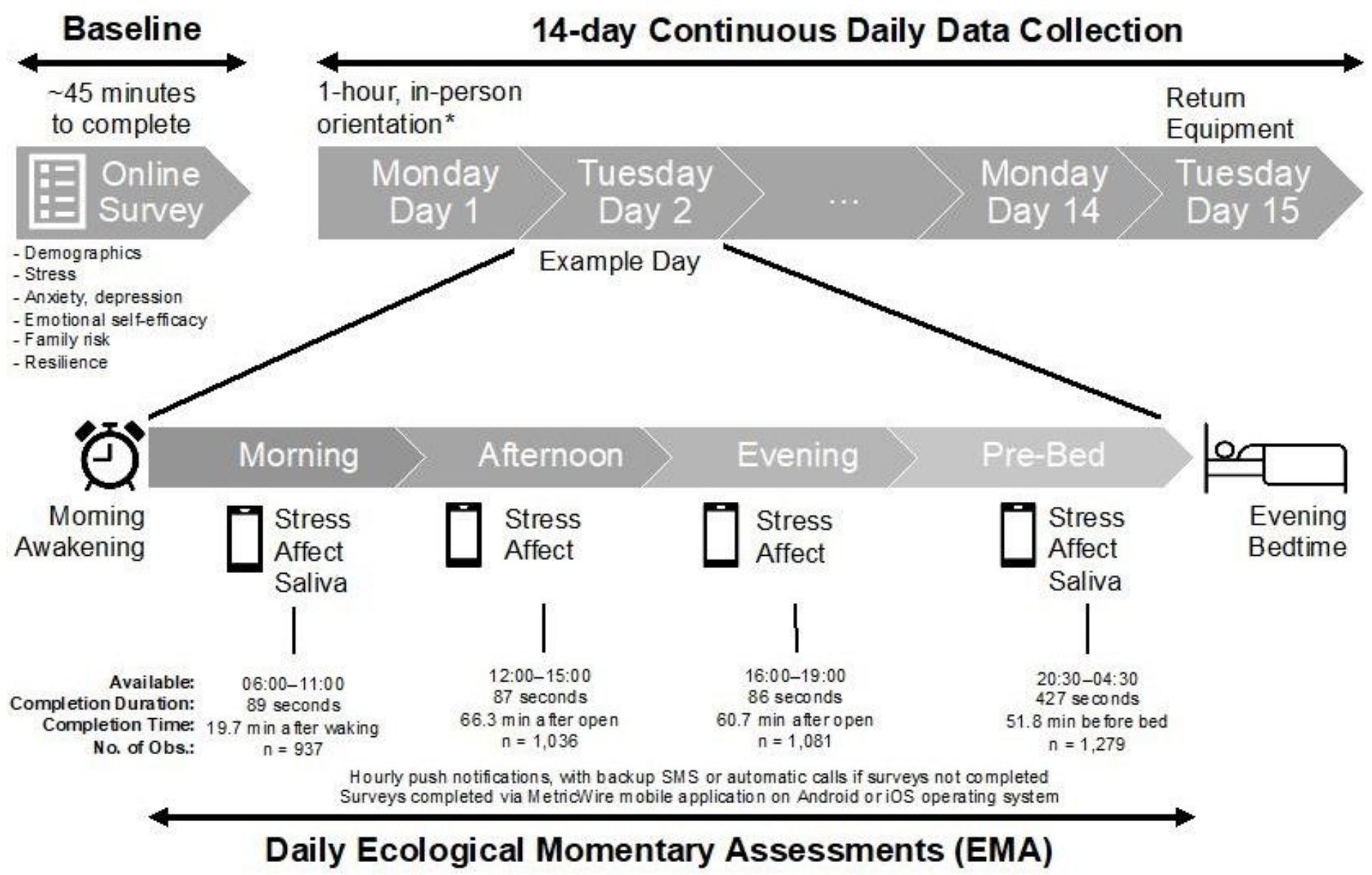

Note. *Participants who joined the study during COVID-19 restrictions were given the instructions through a recorded video and supported through teleconference platform Zoom. 
Study Procedure and Survey Completion. Note. All participants started on Mondays and ended on Mondays, providing 10 weekdays and 4 weekend days. All surveys were closed outside their respective time windows to prevent retrospective reports. Stress and affect survey questions were identical over time to reduce participant burden, with some additional questions (not explored in this study) at the pre-sleep survey, resulting in longer completion time. Median completion time was preferred over mean time as it was possible that participants partially attempted surveys and completed them at a later time, leading to artificially longer completion duration. Participants received hourly push notifications (an average of 4 prompts), with backup SMS or automatic calls if surveys were not completed within time window. Surveys were completed via MetricWire mobile application on Android or iOS operating system. Participants attended a 1-hour orientation session before starting the daily study, where they were trained in data collection protocol and provided with instruction manuals for completing surveys and saliva collection. *Participants who joined the study during COVID-19 restrictions were given the instructions through a recorded video and supported through teleconference platform Zoom. Subjects could reach a member of the research team by telephone if they had questions or problems during the sampling period. This period is expected to be a moderate stress period where university students are addressing daily hassles during an academic period of completing assessments or sitting for mid-semester examinations. All daily studies were timed to start during the academic semester and to avoid starting during holidays or break periods. 

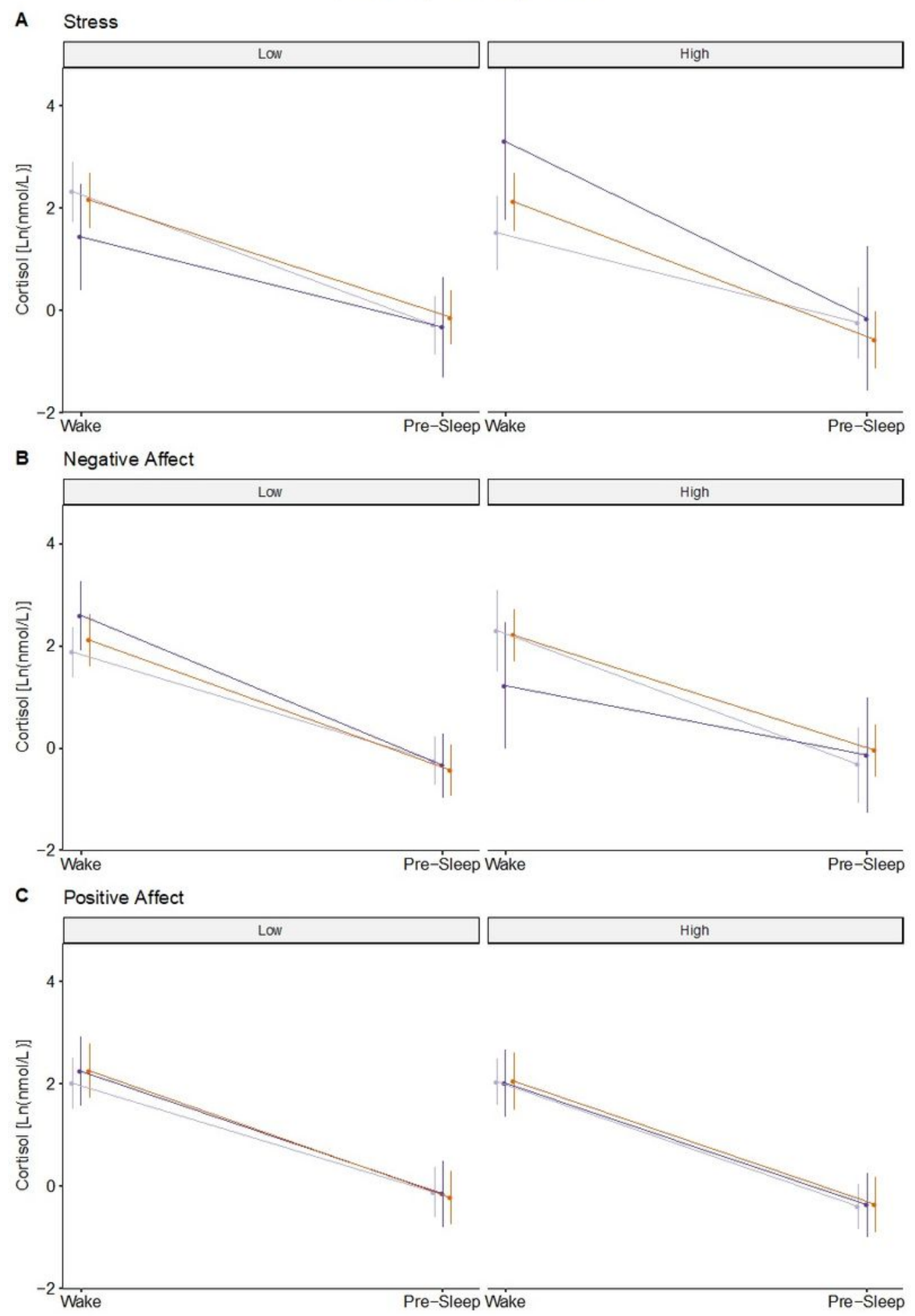

\section{Figure 2}

Three-way Interaction plot for the effects of Group and Perceived Stress/Affect predicting Cortisol Diurnal Slope. Note. High and Low conditions of perceived stress $(4.24,0.45)$, negative $(2.06,1.04)$ and positive affect $(1.57,3.64)$ were determined based on the $90 \%$ and $10 \%$ percentile values of these variables within our sample. 


\section{Supplementary Files}

This is a list of supplementary files associated with this preprint. Click to download.

- SupplementaryNTYCSept21.docx 